Case Report

\title{
Dasatinib-Induced Hypopigmentation in Pediatric Patient with Chronic Myeloid Leukemia: A Case Report and Review of the Literature
}

\author{
Bader Alharbi $\mathbb{D}^{1},{ }^{1}$ Samer Alamri, ${ }^{1}$ Ahmed Mahdi $\mathbb{D}^{,},{ }^{1}$ and Siham Marghalani ${ }^{1,2}$ \\ ${ }^{1}$ King Abdullah International Medical Research Center, King Saud bin Abdulaziz University for Health Sciences, P.O. Box 9515, \\ Jeddah 21423, Saudi Arabia \\ ${ }^{2}$ Department of Dermatology, King Khaled National Guard Hospital, National Guard Health Affairs, P.O. Box 9515, \\ Jeddah 21423, Saudi Arabia
}

Correspondence should be addressed to Bader Alharbi; dr.alharbibader@gmail.com

Received 6 March 2018; Revised 3 June 2018; Accepted 4 June 2018; Published 9 July 2018

Academic Editor: Jacek Cezary Szepietowski

Copyright (C) 2018 Bader Alharbi et al. This is an open access article distributed under the Creative Commons Attribution License, which permits unrestricted use, distribution, and reproduction in any medium, provided the original work is properly cited.

\begin{abstract}
Dasatinib is an oral second-generation multitarget tyrosine-kinase inhibitor (TKI) that is efficacious in treating imatinib-resistant chronic myeloid leukemia (CML) or intolerant cases. Noncutaneous adverse effects with dasatinib are well known in the literature, most commonly cytopenias and fluid retention, while pigmentary abnormalities have rarely been reported. We report the case of a 12-year-old male known case of CML, who presented to dermatology clinic approximately 2 years after initiating dasatinib treatment, with new-onset hypopigmentation of his upper limb, upper chest, and both knees of six months' duration.
\end{abstract}

\section{Introduction}

Chronic myeloid leukemia (CML) is a hematopoietic stem cell malignancy. It usually occurs in an older population with an age of 60 to 65 years [1]. It is considered to be rare among the young population with an incidence of $2 \%$ of all leukemia in an age less than 15 years [2]. CML is a clonal disease that is caused by a gene mutation that consists of a reciprocal translocation between chromosomes 9 and 22, leading to what is known as Philadelphia chromosome $(\mathrm{Ph})$ [3]. Tyrosine kinase inhibitors (TKIs) are currently the mainstay of CML treatment. Dasatinib is an oral multitarget tyrosine-kinase inhibitor. It is efficacious in cases of resistance or intolerance to Imatinib [4]. It works by inhibiting BCRABL mutant forms, Src-family tyrosine kinases, c-Kit, ephrinA2 receptor (EphA2R), and platelet-derived growth factor receptor-B (PDGFR-B). Unlike imatinib, it binds to active and inactive conformations of BCR-ABL [5]. Multiple dermatological side effects such us superficial edema, lichenoid reaction, psoriasis, and Steven-Jonson syndrome have been reported with first generation TKIs like imatinib mesylate [6]. However, depigmentation is reported to be around 41 percent [7]. In contrast, cutaneous side effects of dasatinib have been rarely reported. We report a case of dasatinibinduced hypopigmentation in a young patient with chronic myeloid leukemia and review cases in the literature.

\section{Case}

A 12-year-old male with a history of chronic myeloid leukemia presented to our dermatology clinic with newonset hypopigmented patches that are slowly progressive and of varying sizes of six months' duration on his upper limbs, upper chest, and both knees (Figure 1). Also, two depigmented macules were noted on his upper chest and lower abdomen. The patient denied any rashes or other skin changes and also denied any changes in hair, nail, and mucous membranes. Furthermore, Wood's light examination was negative. The patient was switched to dasatinib, at a dose of 70 mg once per day since two years, due to intolerance to imatinib. There was no personal or family history of autoimmune diseases or pigmentary disorders like vitiligo. The patient denied any use of topical medications or bleaching agents. A $3 \mathrm{~mm}$ punch biopsy from active hypopigmented lesion on 


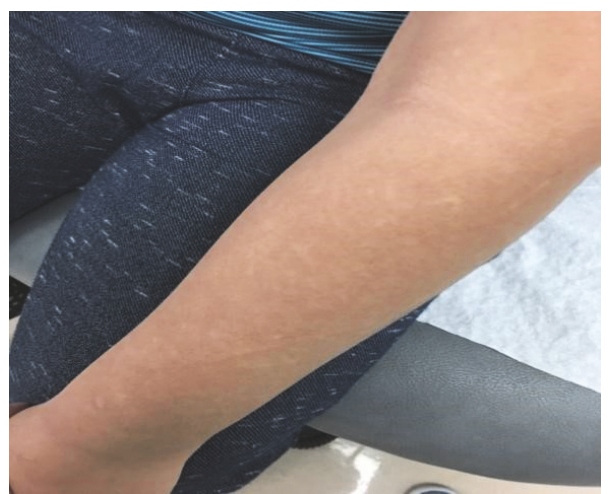

(a)

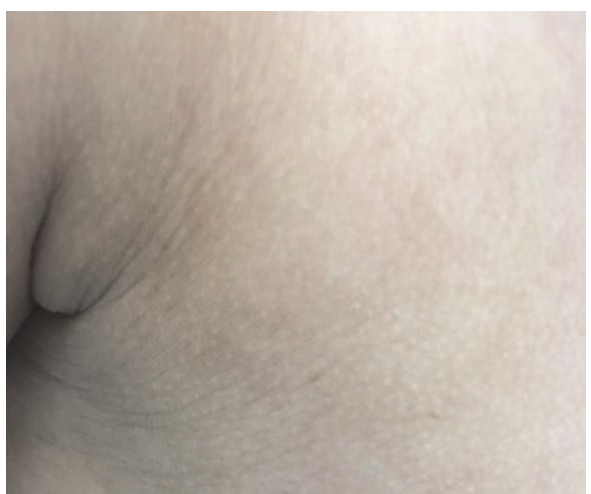

(b)

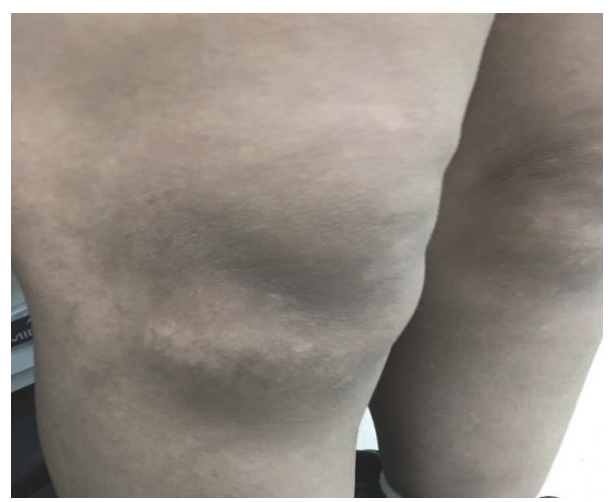

(c)

Figure 1: Hypopigmented areas on the (a) upper limb, (b) upper chest, and (c) both knees.

the abdomen was performed. Histopathologically, it showed decrease melanocytes and basal layer melanin pigmentation. In immunohistochemistry, Melan A stain revealed decreased melanocyte. All positive and negative controls are examined and show appropriate reactivity. The patient was treated with close observation and reassurance. Through it all, the above clinical clues led to a diagnosis of skin depigmentation during dasatinib treatment.

\section{Discussion}

Tyrosine Kinase Inhibitors (TKI) are considered the cornerstone in the treatment of chronic myeloid leukemia (CML). Dasatinib, a second generation TKI, is used as a second line therapy in CML cases where patients are resistant or intolerant to first generation TKI, like imatinib [4]. Likewise, our patient was intolerant to imatinib and switched to dasatinib due to severe bone pain before achieving a complete molecular response. In vitro, dasatinib is considered about 300 times more potent than imatinib; this is due to its ability to bind to both active and inactive conformations of BCRABL [5].

Multiple well known cutaneous adverse effects were noted with TKI treatment, for example, superficial edema, maculopapular rash, pigmentary changes, lichenoid reaction, and psoriasiform rash [6]. These side effects were reported particularly with first generation TKI, namely, imatinib, while few cases were reported about the cutaneous side effects with dasatinib. Nevertheless, noncutaneous adverse effects with dasatinib are well known in the literature, most commonly cytopenias and fluid retention [14]. Pigmentary side effects with imatinib were reported in a study done by Arora et al. in which depigmentation and hyperpigmentation were seen in $40.9 \%$ and $3.6 \%$ of 118 patients, respectively [7].

In addition to BCR-ABL, dasatinib targets multiple tyrosine kinases, such as SCR family kinases, c-Kit, plateletderived growth factor (PDGFR), and ephrin-A receptor kinases. The protooncogene c-Kit and its ligand stem cell factor (SCF) play a crucial role in the proliferation, migration, and survival of melanocytes. Therefore, inhibiting the cKit/SCF signaling pathway is thought to be the reason for pigmentary side effects in a patient receiving TKIs [15]. A clinical example of this signaling pathway is seen in patients with piebaldism, which is an autosomal dominant disorder resulting from a mutation in KIT protooncogene leading to the absence of melanocytes and the appearance of leukoderma on the affected areas [16]. However, dasatinib has a low affinity to c-Kit and PDFGR compared to imatinib, and this is the reason why pigmentary side effects are more pronounced with imatinib compared to dasatinib [6].

The median time for the onset of pigmentary adverse effects is about 2 months after starting TKI therapy (Table 1) [8-13]. Moreover, Webb $\mathrm{K}$ et al. reported that a case with dasatinib induced facial depigmentation after almost 
TABLE 1

\begin{tabular}{|c|c|c|c|c|c|c|}
\hline $\begin{array}{l}\text { Case } \\
\text { number }\end{array}$ & Age & Gender & Diagnosis & Dasatinib dose & $\begin{array}{c}\text { Time to } \\
\text { hypopigmentation } \\
\text { (Months) }\end{array}$ & References \\
\hline $\begin{array}{l}\text { Current } \\
\text { case }\end{array}$ & 12 & Male & $\begin{array}{l}\text { chronic myeloid } \\
\text { leukemia }\end{array}$ & 70 mg once daily & 18 & Current case \\
\hline 1 & 72 & Male & $\begin{array}{c}\text { chronic myeloid } \\
\text { leukemia }\end{array}$ & $100 \mathrm{mg}$ once daily & 37 & {$[8]$} \\
\hline 2 & 52 & Female & Hemangiopericytoma & $70 \mathrm{mg}$ twice daily & 2 & [9] \\
\hline 3 & 27 & Female & $\begin{array}{c}\text { chronic myeloid } \\
\text { leukemia }\end{array}$ & $100 \mathrm{mg}$ once daily & 6 & {$[10]$} \\
\hline 4 & 16 & Male & $\begin{array}{c}\text { Acute lymphoblastic } \\
\text { leukemia }\end{array}$ & $100 \mathrm{mg}$ twice daily & 1 & {$[11]$} \\
\hline 5 & 56 & Female & $\begin{array}{c}\begin{array}{c}\text { chronic myeloid } \\
\text { leukemia }\end{array} \\
\end{array}$ & 70 once daily & 2 & {$[12]$} \\
\hline 6 & 29 & Female & $\begin{array}{l}\text { chronic myeloid } \\
\text { leukemia }\end{array}$ & 70 once daily & 2 & {$[13]$} \\
\hline
\end{tabular}

three years of starting the therapy [8]. In comparison, our patient developed generalized hypopigmentation after about 18 months of switching to dasatinib. The pigmentary changes with TKI appear to be dose-dependent and reversible with a resolution of pigmentary side effects after stopping the treatment [16]. Furthermore, Boudadi et al. reported a case with dasatinib induced hypopigmentation that resolved after stopping the treatment, and then the patient's skin color started to darken beyond her baseline and she experienced diffuse hyperpigmentation. This paradoxical pigmentary changes with TKI were thought to be due to drug-related immune dysregulation in which TKI can act as c-Kit receptor modulator [9].

Regarding the age of patients with dasatinib induced hypopigmentation, our patient is considered the youngest compared to cases reported in the literature (Table 1).

The challenge in the management of pigmentary side effects with TKI is that most patients with hematological malignancies, particularly CML, require the continuation of TKI for long periods even after achieving a complete molecular response. This is because of a high incidence of molecular relapse after withholding the therapy [17]. For this reason, the cessation of dasatinib was not the option in the management for our patient and he was treated with close observation and reassurance.

\section{Conclusion}

Since TKIs are widely used in the treatment of different hematological and nonhematological malignancies, we encourage physicians to take into account the multiple cutaneous side effects that can be caused by this therapy. Additionally, further studies are needed to explore the role of c-Kit/SCF signaling pathway and the role of other factors in the development of pigmentary changes with different TKI generations.

\section{Data Availability}

Data will be available upon request.

\section{Conflicts of Interest}

The authors declare no conflicts of interest.

\section{References}

[1] G. Gugliotta, F. Castagnetti, M. Apolinari et al., "First-line treatment of newly diagnosed elderly patients with chronic myeloid leukemia: Current and emerging strategies," Drugs, vol. 74, no. 6, pp. 627-643, 2014.

[2] R. LAG, M. Smith, J. G. Gurney et al., Eds., Cancer Incidence and Survival among Children and Adolescents: United States SEER Program 1975-1995, vol. 99, National Cancer Institute, 1999.

[3] Nowell P. C. and D. A. Hungerford, "A minute chromosome in human chronic granulocytic leukemia," Science, p. 1497, 132.

[4] A. Hochhaus, S. Saussele, G. Rosti et al., "Chronic myeloid leukaemia: ESMO Clinical Practice Guidelines for diagnosis, treatment and follow-up," Annals of Oncology, vol. 28, pp. iv41iv51, 2017.

[5] M. Lindauer and A. Hochhaus, "Dasatinib," Recent Results in Cancer Research, vol. 184, pp. 83-102, 2010.

[6] I. Amitay-Laish, S. M. Stemmer, and M. E. Lacouture, "Adverse cutaneous reactions secondary to tyrosine kinase inhibitors including imatinib mesylate, nilotinib, and dasatinib," Dermatologic Therapy, vol. 24, no. 4, pp. 386-395, 2011.

[7] B. Arora, L. Kumar, A. Sharma, J. Wadhwa, and V. Kochupillai, "Pigmentary changes in chronic myeloid leukemia patients treated with imatinib mesylate," Annals of Oncology, vol. 15, no. 2, pp. 358-359, 2004.

[8] K. C. Webb, M. Harasimowicz, M. Janeczek, J. Speiser, J. Swan, and R. Tung, "Development of asymmetric facial depigmentation in a patient treated with dasatinib with new-onset hypovitaminosis d: case report and review of the literature," Case Reports in Dermatological Medicine, 2017.

[9] K. Boudadi and R. Chugh, "Diffuse hypopigmentation followed by hyperpigmentation in an African American woman with hemangiopericytoma treated with dasatinib," Journal of Clinical and Diagnostic Research, vol. 8, no. 11, pp. QD01-QD02, 2014.

[10] S. Samimi, E. Chu, J. Seykora et al., "Dasatinib-induced leukotrichia in a patient with chronic myelogenous leukemia," JAMA Dermatology, vol. 149, no. 5, pp. 637-639, 2013. 
[11] V. Brazzelli, V. Grasso, V. Barbaccia et al., "Hair depigmentation and vitiligo-like lesions in a leukaemic paediatric patient during chemotherapy with dasatinib," Acta Dermato-Venereologica, vol. 92, no. 2, pp. 218-219, 2012.

[12] A. Fujimi, S. Ibata, Y. Kanisawa et al., "Reversible skin and hair depigmentation during chemotherapy with dasatinib for chronic myeloid leukemia," The Journal of Dermatology, vol. 43, no. 1, pp. 106-107, 2016.

[13] A. Sun, R. S. Akin, E. Cobos, and J. Smith, "Hair depigmentation during chemotherapy with dasatinib, a dual Bcr-Abl/Src family tyrosine kinase inhibitor," J Drugs Dermatol, vol. 8, no. 4, pp. 395-398, 2009.

[14] S. Shayani, "Dasatinib, a multikinase inhibitor: therapy, safety, and appropriate management of adverse events," Therapeutic Drug Monitoring, vol. 32, no. 6, pp. 680-687, 2010.

[15] J. M. Grichnik, J. A. Burch, J. Burchette, and C. R. Shea, "The $\mathrm{SCF} / \mathrm{KIT}$ pathway plays a critical role in the control of normal human melanocyte homeostasis," Journal of Investigative Dermatology, vol. 111, no. 2, pp. 233-238, 1998.

[16] N. Oiso, K. Fukai, A. Kawada, and T. Suzuki, "Piebaldism," The Journal of Dermatology, vol. 40, no. 5, pp. 330-335, 2013.

[17] I. C. Haznedaroglu, "Current concerns of undertreatment and overtreatment in chronic myeloid leukemia based on European LeukemiaNet 2013 recommendations," Expert Opinion on Pharmacotherapy, vol. 14, no. 15, pp. 2005-2010, 2013. 


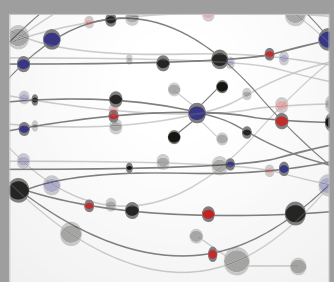

The Scientific World Journal
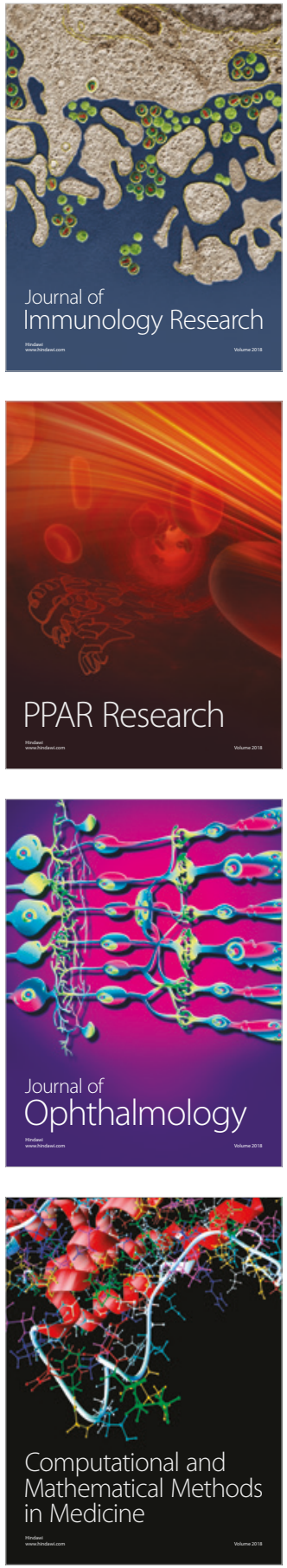

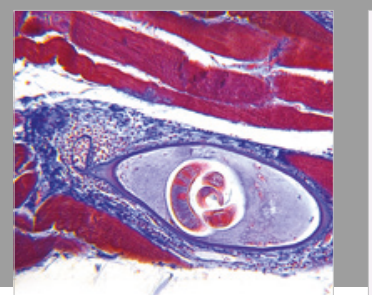

Gastroenterology Research and Practice

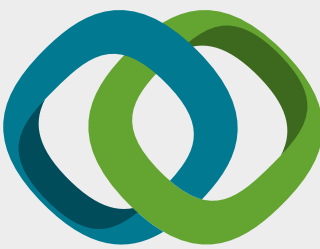

\section{Hindawi}

Submit your manuscripts at

www.hindawi.com
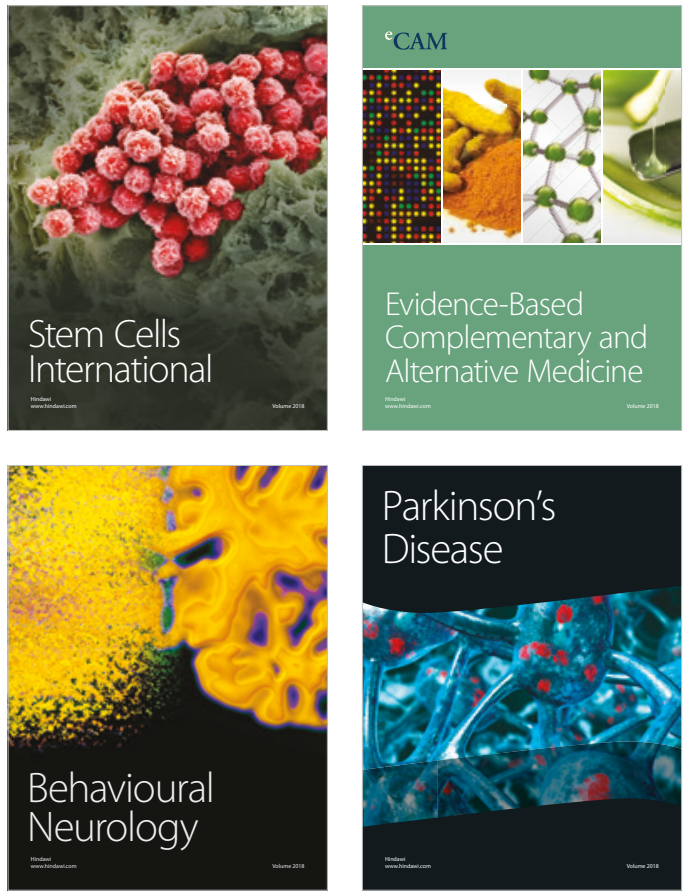

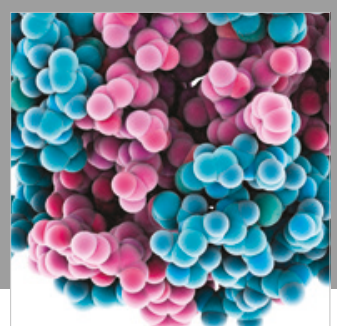

ournal of

Diabetes Research

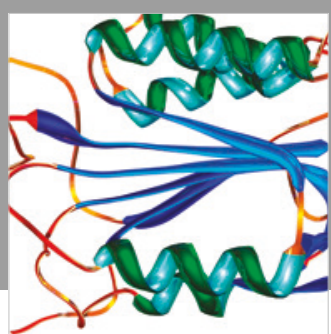

Disease Markers
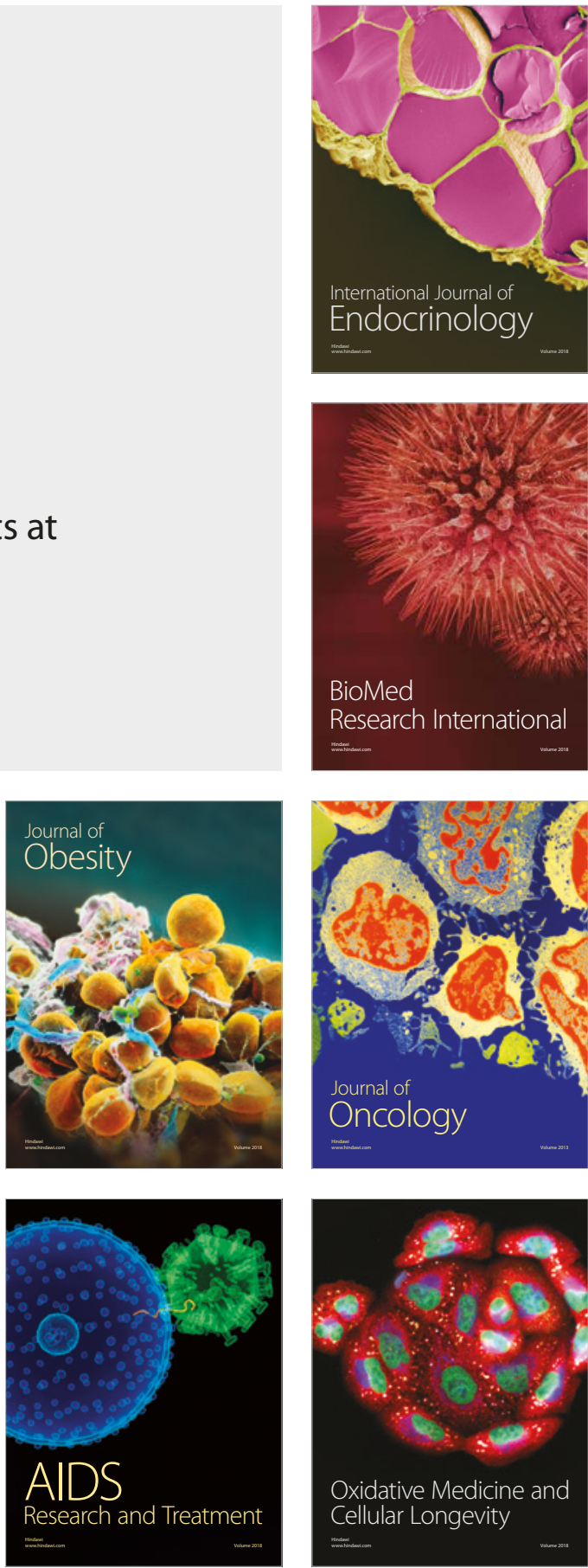